\title{
Factors Affecting Biomedical Ethics Consciousness of College Students
}

\author{
대학생의 생명의료윤리의식에 미치는 영향 \\ Nam Joo Je ${ }^{1}$, Meera Park ${ }^{2}$, Jiwon Yoon ${ }^{3}$ \\ 제남주1, 박미라 ${ }^{2}$, 윤지원 3 \\ ${ }^{1}$ Associate Professor, Dept. Nursing, Changshin University, Korea, jnj4757@cs.ac.kr \\ ${ }^{2}$ Assistant Professor, Dept. Nursing, Changshin University, Korea, minerva32@cs.ac.kr \\ ${ }^{3}$ Assistant Professor, Dept. Korean Education, Changshin University, Korea, jwyoon@cs.ac.kr
}

Corresponding author: Meera Park

\begin{abstract}
This study was conducted on college students to determine their digital media literacy, moral sensitivity, and biomedical ethics consciousness and their relationship. The data collection for this study was conducted April 8, 2021 to April 30, 2021 using online questionnaires for 151 college students in Korea. The collected data were analyzed using IBM SPSS WIN/25.0. The general characteristics and variable were frequency, mean, and standard deviation, the difference of variables according to the general characteristics was analyzed by t-test and one-way ANOVA, and post analysis was analyzed by Scheffe's test. The correlation between each variable was analyzed using Pearson's correlation and the effect on biomedical Ethics consiousness was obtained by regression analysis. Based on the results of the study, it was found that biomedical ethics consciousness had positive correlation with digital media literacy and major sensitivity. The factors that most affect the biomedical Ethics consiousness of the subjects was 'Religious activity-be active', follewed by 'Ethics consciousness stage - Sometimes confused', 'Moral sensitivity'. The explanatory power of the model was $34.2 \%$. Content development that can utilize digital media literacy will be helpful as a way of education to promote university students' biomedical ethics consiciousness. We hope that the results of this study will be used as the basic data for content composition.
\end{abstract}

Keywords: Biomedical Ethics Consciousness, College Students, Digital Media Literacy, Major Sensitivity

요약: 본 연구는 대학생의 디지털미디어 리터러시와 도덕적 민감성, 생명의료윤리의식 정도와 그들간의 관계를 파악하기 위해 시행되었다. 2021년 4월 8일부터 4월 30일까지 151 명의 대학생에게 온라인 설문조사를 시행되었다. 자료분석은 IBM SPSS WIN/25.0. 을 이용하였다. 대상자의 특성과 변수는 빈도분석과 평균, 표준편차를 구하였고, 대상자의 특성에 따른 변수의 차이는 t-test와 ANOVA를 시행하였으며 사후분석으로 Scheffe's test를 시행하였다. 변수 간의 관계는 Pearson's correlation을 하였으며, 생명의료윤리에 미치는 영향은 회귀분석을 시행하였다. 생명의료윤리의식은 디지털미디어리터러시, 도덕적 민감성과 순상관관계가 있었다. 생명의료윤리의식에 가장 영향을 미치는 요인은 '종교활동-활동적'이었고, 그 다음으로 '윤리의식단계-가끔 혼란스럽다', '도덕적 민감성' 순으로 나타났다. 이 모형의 설명력은 $34.2 \%$ 이었다. 추후 대학생의 생명의료 윤리의식을

Received: March 24, 2021; 1st Review Result: May 08, 2021; 2nd Review Result: June 21, 2021 Accepted: July 31, 2021 
함양하는 교육의 한 방법으로 디지털 미디어 리터러시를 활용할 수 있는 콘텐츠 개발이 도움이 될 것이라 생각하며, 본 연구의 결과가 콘텐츠 구성의 기초자료로 사용되기를 기대한다.

핵심어: 대학생, 도덕적 민감성, 디지털미디어리터러시, 생명의료윤리

\section{1. 서론}

\section{1 연구의 필요성}

현대의 생명공학과 의료기술의 발달로 인해 과거에는 생각하지 못했던 새로운 문제가 윤리적 고려의 대상이 되었다. 새롭게 나타난 윤리적 문제를 해결하기 위해 생명윤리학 이 나타나게 되었는데, 생명윤리학은 생명과 관련된 윤리이론을 기존의 생명공학과 의학 에 응용뿐만 아니라, 새롭게 제기된 문제를 비판적으로 검토하고 상황에 적용하는 응용 윤리에 대한 학문이다[1]. 생명윤리는 특정직업을 위한 윤리가 아니라 생명이 있는 모든 것을 위한 윤리이며, 일반 사람들도 가져야 하는 윤리이다. 대학생의 경우 미래사회를 이 끌어나갈 주역 중의 하나로서 이들의 생명윤리의식 함양이 중요하다[2].

생명윤리 문제를 해결하고 상황에 적용하기 위해서는 도덕적 민감성이 필요하다. 도덕 적 민감성은 특정 상황들을 도덕적으로 해석해 낼 수 있는 능력으로, 타인의 요구를 읽 어내며, 도덕적 상황에서 어떻게 자신이 행동할 수 있는가를 생각해 볼 수 있는 능력이 다[3]. 도덕적 행동을 하기 위해서 사전에 합당한 행동인지를 비판적으로 판단하는 과정 이 수반되며[4] 이러한 비판적 사고의 형성과 가치 식별력의 배양은 생명의료윤리의식의 정립과도 중요한 연관성을 갖는다[5]. 도덕적 민감성은 비판적사고와 함께 복잡한 상황에 서의 합리적이고 윤리적 의사결정을 할 수 있도록 돕고 도덕적 민감성과 비판적 사고성 향이 생명의료윤리 의식 정립에 영향을 미칠 수 있다[6].

생명의료윤리는 정보통신기술의 발전과 COVID-19와 같은 상황적 문제로 인한 언택트 시대의 도래 등[7]으로 인해 생명복제, 존엄사, 연명치료 중단 등의 의료현장에서의 윤리 적 문제뿐만 아니라 사이버 공간에서까지 다양한 분야에서 요구된다[8]. 언택드 시대에는 디지털 미디어를 통해 정보를 찾고 타인과 소통하게 되는데, 이 때 필요한 능력을 디지 털 미디어 리터러시라고 말한다[4]. 디지털 미디어 리터러시는 미디어에 대한 접근뿐 아 니라 비판적 해독, 창의적 표현, 참여와 소통을 아우르는 다층적 커뮤니케이션 능력으로, 디지털 미디어 환경에서 반드시 갖추어야 할 필수요건이다[9]. 미디어 활용과 관련된 윤 리교육은 평생 지속하여야 하며, 디지털 미디어 리터러시를 활용한 윤리의식함양 또한 현시대에 필요한 요소라 할 수 있다.

생명의료 윤리와 관련된 선행 연구로는 보건계열과 비보건 계열 혹은 간호학과와 간호 학과가 아닌 학생 간의 생명의료윤리 의식 비교, 간호학과 학생의 생명윤리의식에 미치 는 요인들에 관한 연구들이 주로 이루어져 왔다. 미디어를 이용하여 생명의료윤리의식 향상을 도모한 연구[9]는 있었지만, 디지털 미디어 리터러시와 생명의료윤리의식의 관계 를 확인한 연구는 찾아보기 힘들었다.

이에 대학생을 대상으로 디지털 미디어 리터러시와 도덕적 민감성 및 생명의료윤리의 식의 관계를 확인하고 생명의료윤리의식에 미치는 영향요인을 파악하여 생명의료윤리의 식을 높이기 위한 대책 마련의 기초자료로 활용하고자 한다. 


\section{2 연구목적}

본 연구의 목적은 대학생을 대상으로 디지털 미디어 리터러시, 도덕적 민감성, 비판적 사고성향, 생명의료윤리의식의 정도와 이들 변수 간의 관계 및 생명의료윤리의식의 영향 요인을 파악하기 위함이다.

\section{2. 연구방법}

\section{1 연구설계}

본 연구는 대학생을 대상으로 디지털 미디어 리터러시, 도덕적 민감성, 생명의료윤리의 식의 정도와 변수 간의 관계 및 생명의료윤리의식의 영향요인을 파악하기 위한 서술적 상관관계 연구이다.

\section{2 연구대상자}

연구대상자는 전국의 대학생으로 설문 내용에 대한 이해와 판단이 가능하고 참여에 동 의한 재학생을 대상으로 편의추출 하였다. G*power 3.10 프로그램[10]을 이용하여 회귀분 석에 적합한 표본 수를 선정하기 위하여 유의수준 .05 , 검정력 .80 , 효과크기 .15 , 독립변 수 15 개를 설정하여 계산한 결과 139 명으로 산출되었으나 탈락률 $10 \%$ 를 고려하여 154 명 을 초기대상자로 표집하였으며, 응답이 불성실한 설문지를 제외한 151 명을 최종 분석에 사용하였다.

\section{3 연구도구}

본 연구는 구조화된 설문지를 사용하였으며, 설문지는 제 특성과 디지털 미디어 리터러 시, 도덕적 민감성, 비판적 사고성향, 생명의료윤리의식을 측정하는 123 문항으로 구성하 였다.

\subsection{1 제 특성}

제 특성은 선행연구[11]에서 사용한 문항을 참조하여 성별, 종교활동, 지난학기 성적, 대인관계 갈등 경험, 윤리의식정도, 생명의료윤리교육 유무 등 총 6 문항으로 측정하였다.

\subsection{2 디지털 미디어 리터러시}

디지털 미디어 리터러시는 An [4]이 구성한 디지털 미디어 리터러시 측정도구를 사용하 였다. 도구는 3 개 영역(기회, 능력, 시민성)의 총 49문항으로 구성되어 있으며, “전혀 그렇 지 않다."(1점)에서 “매우 그렇다"(5점)의 5점 Likert 척도이다. 각 설문 문항 점수가 높을 수록 디지털 미디어 리터러시 수준이 높은 것을 의미한다. 본 연구에서는 평균점수를 활 용하였다. 개발 당시 도구의 신뢰도 Cronbach's a=.71 .90이었고, 본 연구에서 신뢰도 Cronbach's $\alpha=.87$ 이었다.

\subsection{3 도덕적 민감성}


도덕적 민감성은 Yoon[12]의 도덕성 척도를 Lee[13]가 재구성한 도구를 사용하였다. 도 구는 총 20 문항으로 구성되어 있으며 “전혀 그렇지 않다.”(1점)에서 “매우 그렇다”(5점)의 5점 Likert 척도이다. 점수가 높을수록 도덕적 민감성이 높음을 의미한다. 본 연구에서는 평균점수를 활용하였다. Lee[13]의 연구에서 신뢰도 Cronbach's $\alpha=80$ 이었고, 본 연구에서 신뢰도 Cronbach's $\alpha=.74$ 이었다.

\subsection{4 비판적 사고성향}

비판적 사고성향은 Yoon[14]이 간호학을 중심으로 개발한 비판적 사고성향 측정 도구를 사용하였다. 도구는 총 27문항으로 구성되어 있으며, “전혀 그렇지 않다.”(1점)에서 “매우 그렇다"(5점)의 5점 Likert 척도이다. 점수가 높을수록 비판적 사고성향이 강함을 의미한 한다. 본 연구에서는 평균점수를 활용하였다. 개발 당시 도구의 신뢰도는 Cronbach's $\alpha=.84$ 이었고 본 연구에서 신뢰도 Cronbach's $\alpha=.89$ 이었다.

\subsection{5 생명의료윤리의식}

생명의료윤리의식은 Lee[15]의 윤리적 가치관 설문지를 Kwon[16]이 수정·보완하고 Je 와 $\operatorname{Park[11]}$ 이 재구성한 생명의료윤리 의식 단축도구를 사용하였다. 도구는 9개 영역(태아의 생명권, 인공임신중절, 인공수정, 태아 진단, 신생아의 생명권, 안락사, 장기이식, 뇌사, 인 간 생명공학)의 총 21 문항으로 구성되어 있다. 각 문항은 Likert 4점 척도로, ‘찬성' 4점, ‘대 체로 찬성’3점, ‘대체로 반대’2점, ‘반대’1점으로 점수화하고 부정 문항은 역산처리 하였다. 점수가 높을수록 생명의료윤리 의식이 높음을 의미한다. 본 연구에서는 평균점수를 활용 하였다. Je와 Park[11]의 연구에서 신뢰도 Cronbach's $\alpha=.80$ 이었고, 본 연구에서 신뢰도 Cronbach' $\alpha=.96$ 이었다.

\section{4 자료수집기간 및 방법}

자료수집은 C대학교 생명윤리위원회 승인(CSIRB-R2021012)을 받았으며, 2021년 4월 8일 부터 4월 30일까지이었고, 연구자는 전국 대학의 연구 관련 담당부서 담당자에게 연구를 설명하고 허가를 득한 후 연구공고문을 공지하였다. 연구공고문에 구글설문지 URL을 게 시하였고, 이를 보고 접속한 대상자에게 설문조사를 시행하였다. URL의 안내문에 연구의 목적과 익명성 보장 및 진행 절차 등에 대한 설명사항을 기재하였으며, 온라인으로 연구 참여 동의서를 받았다. 설문 종료 후 연구참여 동의서에 기입된 번호로 소정의 선물을 보냈으며, 구글설문지는 개인정보와 관련된 부분을 삭제한 후 보관하여 익명성을 유지하 였다.

\section{5 자료분석}

수집된 자료는 IBM SPSS WIN/25.0을 사용하여 분석하였다. 결과에 대한 유의수준은 .05 로 측정하였고, 측정도구의 신뢰도를 구하였다. 대상자의 제 특성은 빈도(백분율), 각 변 수는 평균과 표준편차를 구하였다. 대상자의 제 특성에 따른 변수의 차이는 t-test, one-way ANOVA로 측정하였고, 변수의 상관관계는 Pearson's correlation coefficient를 구하였다. 생명 의료윤리의식에 미치는 영향 요인은 multiple regression(step-wise)을 이용하여 분석하였다. 


\section{3. 연구결과}

\section{1 대상자의 제 특성}

대상자의 성별은 대상자의 $70.9 \%$ 가 '여성'이었다(107명). 종교활동 정도는'활동적이다' 부터 '거의 안한다'까지 비슷하게 분포되었다. 지난학기 성적은 3.5 이상이 120 명 $(79.5 \%)$ 으 로 많은 수를 차지했으며, 대인관계 갈등 경험은 '가끔 있다'가 104명 $68.9 \%)$ 으로 가장 많 았고 전혀없는 경우는 40 명 $(26.5 \%)$ 이었다. 생명의료윤리의식 단계는 '상황에 따라 달라짐' 이 80 명(53.0\%)로 가장 많았고, 생명의료윤리교육은 '없음'이 113 명(74.8\%)으로 많았다 [Table 1].

[표 1] 대상자의 제특성

[Table 1] Characteristics of Participants ( $\mathrm{N}=151)$

\begin{tabular}{|l|c|c|}
\hline Variable & Categories & $\mathrm{n}(\%)$ \\
\hline \multirow{3}{*}{ Gender } & Male & $44(29.1)$ \\
\hline \multirow{3}{*}{$\begin{array}{l}\text { Religious activity } \\
(53 \text { persons })\end{array}$} & Female & $107(70.9)$ \\
\cline { 2 - 3 } & Be active & $10(6.6)$ \\
\cline { 2 - 3 } & Average & $18(11.9)$ \\
\cline { 2 - 3 } $\begin{array}{l}\text { Last semester } \\
\text { rating }\end{array}$ & Sometimes & $14(9.3)$ \\
\hline \multirow{2}{*}{$\begin{array}{l}\text { Conflict } \\
\text { experience }\end{array}$} & Rarely do & $11(7.3)$ \\
\hline \multirow{3}{*}{ Ethics consciousness stage } & $<3.5$ & $31(20.5)$ \\
\cline { 2 - 3 } & None & $120(79.5)$ \\
\cline { 2 - 3 } & Sometimes & $40(26.5)$ \\
\hline \multirow{2}{*}{ Biomedical Ethics Education } & Frequent & $104(68.9)$ \\
\cline { 2 - 3 } & Sometimes confused & $7(4.6)$ \\
\cline { 2 - 3 } & Depends on the situation & $33(21.9)$ \\
\hline
\end{tabular}

\section{2 디지털 미디어 리터러시, 도덕적 민감성, 비판적 사고성향, 생명의료윤리의식}

대상자의 디지털 미디어 리터러시 정도는 평균 3.68점(5점 만점)이었다. 디지털 미디어 리터러시 척도의 하위영역을 보면 능력영역이 평균 3.88점(5점 만점)으로 가장 높았고, 기 회영역 평균 3.84점(5점 만점), 시민성영역 평균 2.88점(5점 만점) 순으로 나타났다. 각 영 역별로 세부적으로 보면 기회영역에서는 이용기회(평균 4.35점)가, 능력영역에서는 비판적 이해(평균 4.05점)가, 시민성영역에는 관용성(평균 3.56점)이 가장 높았다.

도덕적 민감성은 평균 3.33점(5점 만점)이었으며 비판적 사고성향은 평균 3.57점(5점 만 점)이었다.

생명의료윤리의식은 평균 2.97점(4점 만점)이었다. 생명의료윤리의식의 하위영역 중에서 신생아의 생명권(평균 3.59점), 태아진단(평균 3.47점) 정도가 높았으며, 인공임신중절(평균 
2.02점), 안락사와 태아의 생명권(평균 2.71점) 정도가 낮았다[Table 2].

[표 2] 변수의 정도

[Table 2] Descriptive Statistics of Variables ( $\mathrm{N}=151)$

\begin{tabular}{|c|c|c|c|c|}
\hline \multicolumn{2}{|c|}{ Variables } & Mean \pm SD & $\min$ & Max \\
\hline \multicolumn{2}{|l|}{ Digital media literacy } & $3.68 \pm 0.30$ & 2.78 & 4.47 \\
\hline \multirow{2}{*}{ Opportunity Area } & Opportunity to use & $4.35 \pm 0.43$ & 3.00 & 5.00 \\
\hline & Educational opportunities & $3.33 \pm 0.77$ & 1.00 & 5.00 \\
\hline \multirow{3}{*}{ Ability area } & Critical understanding & $4.05 \pm 0.46$ & 2.90 & 5.00 \\
\hline & Use and expression & $3.74 \pm 0.65$ & 1.60 & 5.00 \\
\hline & Compliance with the norms & $3.85 \pm 0.71$ & 2.20 & 5.00 \\
\hline \multirow{3}{*}{ Citizenship area } & Forgiveness & $3.56 \pm 0.60$ & 1.00 & 5.00 \\
\hline & Participation & $2.50 \pm 0.91$ & 1.00 & 5.00 \\
\hline & Publicity & $2.58 \pm 0.80$ & 1.00 & 4.33 \\
\hline \multicolumn{2}{|l|}{ Moral sensitivity } & $3.33 \pm 0.37$ & 2.60 & 4.35 \\
\hline \multicolumn{2}{|c|}{ Critical thinking tendency } & $3.57 \pm 0.41$ & 2.56 & 4.67 \\
\hline \multicolumn{2}{|c|}{ Biomedical ethics consciousness } & $2.97 \pm 0.29$ & 2.33 & 3.76 \\
\hline \multicolumn{2}{|c|}{ The right to life of the fetus } & $2.71 \pm 0.70$ & 1.00 & 4.00 \\
\hline \multicolumn{2}{|c|}{ Artificial abortion (the higher the score, the opposite) } & $2.02 \pm 0.61$ & 1.00 & 4.00 \\
\hline \multicolumn{2}{|c|}{ Artificial insemination } & $2.85 \pm 0.65$ & 1.00 & 4.00 \\
\hline \multicolumn{2}{|l|}{ Fetal diagnosis } & $3.47 \pm 0.51$ & 2.00 & 4.00 \\
\hline \multicolumn{2}{|c|}{ Newborn's right to life } & $3.59 \pm 0.54$ & 1.00 & 4.00 \\
\hline \multicolumn{2}{|c|}{ Euthanasia (higher score, opposite) } & $2.71 \pm 0.70$ & 1.00 & 4.75 \\
\hline \multicolumn{2}{|l|}{ Organ transplant } & $3.23 \pm 0.59$ & 2.00 & 4.00 \\
\hline \multicolumn{2}{|l|}{ Brain death } & $2.99 \pm 0.60$ & 1.50 & 4.00 \\
\hline \multicolumn{2}{|c|}{ Human biotechnology } & $3.09 \pm 0.63$ & 2.00 & 4.75 \\
\hline
\end{tabular}

3.3 대상자의 제 특성에 따른 대학생의 디지털 미디어 리터러시, 도덕적 민감성, 비판적 사고성향, 생명의료윤리의식

대상자의 제 특성에 따른 디지털 미디어 리터러시, 도덕적 민감성, 비판적 사고성향, 생명의료윤리의식은 Table 3 과 같다. 디지털 미디어 리터러시는 성별 $(\mathrm{t}=-3.55, \mathrm{p}=.001)$, 직전학기 성적 $(\mathrm{t}=-2.90, p=.004)$, 생명의료윤리교육 경험 $(\mathrm{t}=2.12, p=.035)$ 에 따라 통계적으로 유의한 차이가 있었다. 도덕적 민감성은 성별 $(\mathrm{t}=-3.70, p<.001)$, 종교활동 정도 $(\mathrm{F}=3.16$, $p=.032$ )에 따라 유의한 차이가 있었다. 종교활동의 경우 사후분석 결과 '활동적'이 ‘보통'보다 높았다 학점 $(\mathrm{t}=-2.42, p=.016)$ 과 대인관계 갈등 경험에 따라 유의한 차이가 있었으나 $(\mathrm{F}=3.83, p=.024)$, 대인관계 갈등 경험의 경우 사후분석결과 유의한 차이는 없었다. 윤리의식 정도에 따라 유의한 차이가 있었으나 $(\mathrm{F}=3.46, p=.034)$, 사후분석결과 그룹간 유의한 차이가 없었다.

비판적 사고성향은 종교활동 정도에 따라 유의한 차이가 있었고 $(\mathrm{F}=3.35, p=.026)$ 사후분석 결과 ‘활동적이다’가 '가끔한다’ 보다 높았다. 
생명의료윤리의식은 종교활동 정도에 따라 유의한 차이가 있었고( $\mathrm{F}=4.42, p=.008)$. 사후분석 결과 '활동적이다'가 '가끔한다' 보다 높았다. 또한, 생명의료윤리교육 경험에 따라 유의한 차이가 있었다 $(\mathrm{t}=2.12, p=.035)$. [Table 3].

[표 3] 대상자의 특성에 따른 디지털 미디어 리터러시, 도덕적 민감성, 비판적 사고성향, 생명의료윤리의식

[Table 3] Digital Media Literacy, Moral Sensitivity, Critical Thinking Tendency, and Biomedical Ethics Consciousness according to General Characteristics $\quad(\mathrm{N}=151)$

\begin{tabular}{|c|c|c|c|c|c|c|c|c|c|}
\hline \multirow[t]{2}{*}{ Variable } & \multirow[t]{2}{*}{ Categories } & \multicolumn{2}{|c|}{ Digital media literacy } & \multicolumn{2}{|c|}{ Moral sensitivity } & \multicolumn{2}{|c|}{$\begin{array}{c}\text { Critical thinking } \\
\text { tendency }\end{array}$} & \multicolumn{2}{|c|}{$\begin{array}{l}\text { Biomedical ethics } \\
\text { consciousness }\end{array}$} \\
\hline & & Mean \pm SD & $\mathrm{t}$ or $\mathrm{F}(p)$ & Mean \pm SD & $\mathrm{t}$ or $\mathrm{F}(p)$ & Mean \pm SD & $\mathrm{t}$ or $\mathrm{F}(p)$ & Mean \pm SD & $\mathrm{t}$ or $\mathrm{F}(p$ \\
\hline \multirow[t]{2}{*}{ Gender } & Male & $3.55 \pm 0.33$ & \multirow{2}{*}{$\begin{array}{l}-3.55 \\
(.001)\end{array}$} & $3.16 \pm 0.34$ & \multirow{2}{*}{$\begin{array}{c}-3.70 \\
(<.001)\end{array}$} & $3.58 \pm 0.44$ & \multirow{2}{*}{$\begin{array}{c}0.16 \\
(.872)\end{array}$} & $2.94 \pm 0.34$ & \multirow{2}{*}{$\begin{array}{l}-.78 \\
(.438)\end{array}$} \\
\hline & Female & $3.73 \pm 0.27$ & & $3.40 \pm 0.36$ & & $3.57 \pm 0.40$ & & $2.99 \pm 0.26$ & \\
\hline \multirow{4}{*}{$\begin{array}{l}\text { Religious } \\
\text { activity } \\
\text { (53 persons) } \\
*\end{array}$} & 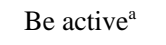 & $3.84 \pm 0.38$ & \multirow{4}{*}{$\begin{array}{c}1.53 \\
(.217)\end{array}$} & $3.65 \pm 0.43$ & \multirow{4}{*}{$\begin{array}{c}3.16 \\
(.032) \\
a>b\end{array}$} & $3.85 \pm 0.36$ & \multirow{4}{*}{$\begin{array}{c}3.35 \\
(.026) \\
a>c\end{array}$} & $3.25 \pm 0.27$ & \multirow{4}{*}{$\begin{array}{c}4.42 \\
(.008) \\
a>c\end{array}$} \\
\hline & Average $^{b}$ & $3.59 \pm 0.37$ & & $3.22 \pm 0.28$ & & $3.48 \pm 0.45$ & & $2.94 \pm 0.25$ & \\
\hline & Sometimes $^{\mathrm{c}}$ & $3.71 \pm 0.34$ & & $3.33 \pm 0.46$ & & $3.34 \pm 0.42$ & & $2.85 \pm 0.27$ & \\
\hline & Rarely do ${ }^{\mathrm{d}}$ & $3.58 \pm 0.17$ & & $3.26 \pm 0.25$ & & $3.37 \pm 0.38$ & & $3.07 \pm 0.35$ & \\
\hline \multirow{2}{*}{$\begin{array}{l}\text { Last semes } \\
\text { ter rating }\end{array}$} & $<3.5$ & $3.54 \pm 0.26$ & \multirow{2}{*}{$\begin{array}{l}-2.90 \\
(.004)\end{array}$} & $3.18 \pm 0.32$ & \multirow{2}{*}{$\begin{array}{l}-2.42 \\
(.016)\end{array}$} & $3.49 \pm 0.36$ & \multirow{2}{*}{$\begin{array}{l}-1.14 \\
(.252)\end{array}$} & $3.03 \pm 0.31$ & \multirow{2}{*}{$\begin{array}{c}1.23 \\
(.219)\end{array}$} \\
\hline & $\geq 3.5$ & $3.71 \pm 0.30$ & & $3.36 \pm 0.38$ & & $3.59 \pm 0.42$ & & $2.96 \pm 0.28$ & \\
\hline \multirow{3}{*}{$\begin{array}{l}\text { Conflict } \\
\text { experience }\end{array}$} & None & $3.68 \pm 0.31$ & \multirow{3}{*}{$\begin{array}{c}0.76 \\
(.466)\end{array}$} & $3.40 \pm 0.38$ & \multirow{3}{*}{$\begin{array}{c}3.83 \\
(.024)\end{array}$} & $3.58 \pm 0.47$ & \multirow{3}{*}{$\begin{array}{c}0.24 \\
(.786)\end{array}$} & $3.01 \pm 0.35$ & \multirow{3}{*}{$\begin{array}{c}0.67 \\
(.511)\end{array}$} \\
\hline & Sometimes & $3.67 \pm 0.29$ & & $3.28 \pm 0.33$ & & $3.56 \pm 0.36$ & & $2.96 \pm 0.25$ & \\
\hline & Frequent & $3.82 \pm 0.41$ & & $3.61 \pm 0.65$ & & $3.67 \pm 0.74$ & & $3.02 \pm 0.45$ & \\
\hline \multirow{3}{*}{$\begin{array}{l}\text { Ethics } \\
\text { consciousne } \\
\text { ss stage* }\end{array}$} & $\begin{array}{l}\text { Very well } \\
\text { established }^{\text {a }}\end{array}$ & $3.74 \pm 0.36$ & \multirow[t]{3}{*}{$\begin{array}{c}2.26 \\
(.107)\end{array}$} & $3.43 \pm 0.40$ & \multirow[t]{3}{*}{$\begin{array}{c}3.46 \\
(.034)\end{array}$} & $3.62 \pm 0.50$ & \multirow[t]{3}{*}{$\begin{array}{c}0.53 \\
(.587)\end{array}$} & $3.11 \pm 0.35$ & \multirow{3}{*}{$\begin{array}{c}5.23 \\
(.006) \\
a>c\end{array}$} \\
\hline & $\begin{array}{l}\text { Sometimes } \\
\text { confused }^{\mathrm{b}}\end{array}$ & $3.73 \pm 0.30$ & & $3.40 \pm 0.38$ & & $3.60 \pm 0.37$ & & $2.95 \pm 0.25$ & \\
\hline & $\begin{array}{l}\text { Depends on } \\
\text { the situation }\end{array}$ & $3.63 \pm 0.26$ & & $3.25 \pm 0.34$ & & $3.54 \pm 0.39$ & & $2.93 \pm 0.26$ & \\
\hline \multirow{2}{*}{$\begin{array}{l}\text { Biomedical } \\
\text { Ethics } \\
\text { Education }\end{array}$} & Haven & $3.77 \pm 0.29$ & \multirow{2}{*}{$\begin{array}{c}2.12 \\
(.035)\end{array}$} & $3.32 \pm 0.46$ & \multirow{2}{*}{$\begin{array}{l}-0.09 \\
(.926)\end{array}$} & $3.59 \pm 0.42$ & \multirow{2}{*}{$\begin{array}{c}0.39 \\
(.697)\end{array}$} & $3.06 \pm 0.31$ & 2.12 \\
\hline & None & $3.65 \pm 0.30$ & & $3.33 \pm 0.34$ & & $3.56 \pm 0.41$ & & $2.95 \pm 0.27$ & \\
\hline
\end{tabular}

* Scheffé test

\section{4 디지털 미디어 리터러시, 도덕적 민감성, 생명의료윤리의식 상관관계}

대상자의 디지털 미디어 리터러시, 도덕적 민감성, 비판적 사고성향, 생명의료윤리의식 의 상관관계는 Table 4 와 같다. 디지털 미디어 리터러시는 도덕적 민감성 $(\mathrm{r}=.55, \mathrm{p}<.001)$, 비 판적 사고성향 $(\mathrm{r}=.43, p<.001)$, 생명의료윤리의식 $(\mathrm{r}=.23, p=.004)$ 과 순상관관계가 있었다. 도덕 적 민감성은 비판적 사고성향 $(\mathrm{r}=.36, p<.001)$, 생명의료윤리의식 $(\mathrm{r}=.42, p<.001)$ 과 순상관관계 가 있었다. 생명의료윤리의식은 비판적 사고성향 $(\mathrm{r}=.19, p=.018)$ 과 순상관관계가 있었다 [Table 4].

\section{[표 4] 변수 간의 상관관계}

[Table 4] Correlation among the Research Variables $\quad(\mathrm{N}=151)$ 


\begin{tabular}{|c|c|c|c|c|}
\hline & Digital media literacy & Moral sensitivity & $\begin{array}{c}\text { Critical thinking } \\
\text { tendency }\end{array}$ & $\begin{array}{c}\text { Biomedical ethics } \\
\text { consciousness }\end{array}$ \\
\cline { 2 - 5 } & \multicolumn{4}{|c|}{$\mathrm{r}(\mathrm{p})$} \\
\hline Digital media literacy & 1 & 1 & & \\
\hline Moral sensitivity & $.55(<.001)$ & $.36(<.001)$ & 1 & 1 \\
\hline $\begin{array}{c}\text { Critical thinking tendency } \\
\text { Biomedical ethics } \\
\text { consciousness }\end{array}$ & $.43(<.001)$ & $.42(<.001)$ & $.19(.018)$ & \\
\hline
\end{tabular}

\section{5 생명의료윤리의식에 영향을 미치는 요인}

대상자의 생명의료윤리의식에 영향을 미치는 요인을 확인하기 위해 생명의료윤리의식 과 상관관계가 있었던 종교활동, 윤리의식, 생명의료윤리교육 경험, 디지털미디어리터러 시, 도덕적 민감성, 비판적사고성향을 독립변수로 투입하였다. 종교활동, 윤리의식단계, 생명의료윤리교육 경험은 더미변수 처리하였다. 단계적(step-wise) 방식으로 Multiple regression analysis를 실시하였다. 다중공선성의 경우 공차한계 .85-.96로 0.1 이상이고, 분산 팽창계수 VIF (Variance Inflation Factor)는 1.04-1.23으로 10 이상을 넘지 않으므로 다중 공선 성의 문제가 없었다. 또한 잔차의 자기상관성은 Durbin-Watson Test 결과 $\mathrm{d}=2.225$ 으로 수용 기준에 부합하므로 자기상관성이 없어서 모형이 성립하였다.

대상자의 생명의료윤리의식에 가장 영향을 미치는 요인은 종교활동-활동적 $(\beta=.250$, $p=.046)$ 이었으며, 그 다음으로 윤리의식단계-때때로 혼란스러움 $(\beta=-.395, p=.001)$, 도덕적 민감성 $(\beta=.388, p=.003)$ 순이었다. 모형의 설명력은 $34.2 \%$ 이었다 $(\mathrm{F}=10.01, p=.001)$ [Table 5].

[표 5] 생명의료윤리의식의 회귀분석

[Table 5] Multiple Regression Analysis on Biomedical Ethics Consciousness ( $\mathrm{N}=151$ )

\begin{tabular}{|l|c|c|c|c|c|}
\hline & $\mathrm{B}$ & $\mathrm{SE}$ & $\beta$ & $\mathrm{t}$ & $p$ \\
\hline (Constant) & 1.999 & .327 & & 6.11 & $<.001$ \\
\hline Religious activity - Be active & 0.198 & 097 & .250 & 2.05 & .046 \\
\hline Ethics consciousness stage - Sometimes confused & -0.271 & .079 & -.395 & -3.44 & .001 \\
\hline Moral sensitivity & 0.313 & .100 & .388 & 3.11 & .003 \\
\hline \multicolumn{2}{|r|}{$\mathrm{R}^{2}=.380$, Adj $\mathrm{R}^{2}=.342, \mathrm{~F}=10.01, p=.001$} \\
\end{tabular}

*Dummy variable

\section{4. 결론}

본 연구에서 생명의료윤리의식은 디지털 미디어 리터러시, 도덕적 민감성과 순상관관계가 있었으며, 이는 선행연구[17][18]의 연구와 유사한 결과이다. 선행연구에서 미디어 리터러시 활용이 도덕적 민감성과 관련있다고 보고하였고[17], 디지털 미디어 리터러시는 윤리의식을 가지고 상호공감하는 역량이라고 하며 윤리의식의 필요성을 언급하여[18] 윤리의식과 도덕적 민감성, 미디어 리터러시의 연관성을 확인하였다. 
본 연구는 COVID-19로 인해 대학교육이 미디어 콘텐츠를 활용한 비대면수업으로 이뤄지고 있는 시점에 진행된 연구로 미디어 리터러시가 기존보다 높아진 상태에서 시작되었다. 언택트 수업에서는 디지털 미디어를 통해 정보를 찾고 타인과 소통하게 되는데 이 과정에서 윤리의식을 가지고 적절한 정보를 선별하여 선택할 수 있어야 하여, 올바른 미디어 리터러시 확립이 이러한 점에서 도움이 된다.

생명의료윤리의식에 영향을 미치는 요인은 종교활동과 윤리의식단계, 도덕적 민감성이었다. 인간존중과 생명의 존엄성을 다루는 생명의료윤리와 종교가 상응하는 부분이 있어 종교활동이 생명의료윤리의식과 관련있다고 생각된다. 윤리의식단계 역시 생명의료윤리의식에 영향을 미치는데 윤리의식단계의 경우 비판적 사고를 가지고 상황을 판단하고 결정하는 과정 중에서 확립될 수 있어서 관련 교육의 반복이 도움이 될 것이다. 현 언택트상황과 같이 미디어를 통해 정보를 찾고 타인과 소통하는 상황이 많아지는 경우에는 디지털 미디어 리터러시의 확립 또한 중요한 요소라 할 수 있다. 선행연구[19]에서는 디지털 미디어 리터러시 수준이 높은 경우 온라인 상에서 긍정적인 기회를 많이 만들어낸다고 하였으므로, 디지털 미디어 리터러시를 활용한 생명의료 윤리의식 교육을 시행한다면 교육의 효과를 높일 수 있을 것으로 생각된다.

추후 대학생의 생명의료윤리의식을 함양하는 교육의 한 방법으로 디지털 미디어 리터러시를 활용할 수 있는 콘텐츠 개발에 도움이 될 것이라 생각하며, 본 연구의 결과가 콘텐츠 구성의 기초자료로 사용되기를 기대한다. 또한, 본 연구는 151 명의 대학생을 대상으로 진행하였으므로 일반화하기에 어려움이 있다. 본 연구의 한계점을 보완하여 향후 폭넓은 대상자와 변수를 추가하여 다양한 연구가 이루어지길 제언한다.

\section{5. 감사의 글}

This research was conducted as a research project of the Korea Research Foundation (NRF2019R1G1A108915412).

\section{References}

[1] K. J. Lee, E. Lee, Y. S. Park, Comparison on Influencing Factors on Consciousness of Biomedical Ethics in Nursing Students and General Students, Journal of Digital Convergence, (2016), Vol.14, No.12, pp.377-388, DOI: http://dx.doi.org/10.14400/JDC.2016.14.12.377

[2] B. W. So, H. S. Park, A Study on the Bioethics Consciousness of University Students: Suggestions for Character Education for University Students, CATHOLIC THEOLOGY AND THOUGHT, (2004), Vol.30, pp.139-178.

[3] P. S. Thompkins, Rhetorical Listening and Moral Sensitivity, Journal of Listening, (2009), Vol.23, No.1, pp.60-79.

[4] J. I. Ahn, A Study on the Age Difference of Digital Media Literacy, Korean Journal of the Learning Sciences, (2013), Vol.7, No.1, pp.1-21.

[5] D. Buckingham, Beyond Technology: Re-thinking Learning in the Age of Digital Culture, Youth Media Democracy: Perceptions of New Literacies, (2008), Ireland: Centre for Social and Educational Research, pp.36-42.

[6] E. A. Kim, H. Y. Park, S. E. Choi, The Influence of Moral Sensitivity and Critical Thinking Dispositions on Biomedical Ethics Awareness of Nursing Students, The Korean Society for Medical Ethics, (2014), Vol.17, No.2, pp.144-158.

[7] J. Yoon, N. J. Je, M. Park, Correlation between Major Suitability, Major Satisfaction, Self-leadership, and Teaching Presence of College Students in Online Learning Environments, Asia-Pacific Journal of Educational Management Research, (2021), Vol.6, No.1, pp.27-34, DOI: 10.21742/AJEMR.2021.6.1.03 
[8] S. Y. Moon, A Study on Bio-ethics in University Education, Journal of the Korean Bioethics Association, (2009), Vol.10, No.2, pp.13-24.

[9] J. H. Kim, M. S. Kim, R. K. Hong, J. W. Ko, The Effects of User and Social Characteristics on Continuous Use Intention among Corporate Mobile SNS Users - With a Focus on Extended Technological Acceptance Model, International Journal of Smart Business and Technology, (2019), Vol.7, No.2, pp.55-60, DOI: 10.21742/IJSBT.2019.7.2.06

[10] F. Faul, E. Erdfelder, A. Buchner, A. G. Lang, Statistical power analyses using G* Power 3.1 : tests for correlation and regression analyses, Behavior research methods, (2009), Vol.41, No.4, pp.1149-1160.

[11] N. J. Je, M. R. Park, Develop and Evaluate the Short Form Biomedical Ethics Tool for Medical Workers In Convergence Era, Journal of Digital Convergence, (2020), Vol.18, No.1, pp.219-229.

[12] M. L. Yoon, The Study on The Effectiveness of Middle School Student's Adolescent Voluntary Activity, Master's Thesis, Honam University, (2002)

[13] H. Lee, The Effect of Parenting Behaviors on the Cyber Delinquency in Adolescents-The Mediating Effect of Moral Sensitivity-, Journal of Family Relations, (2017), Vol.22, No.2, pp.51-69. DOI: 10.21321/jfr.22.2.51

[14 ] J. Yoon, Development of an Instrument for the Measurement of Critical Thinking Disposition : In Nursing, Doctorial Dissertation, Catholic University, (2004)

[15] Y. S. Lee, A Study of the Ethical Values of Korean Nurses, Journal of Nursing Academic Sociaty, (1990). Vol.20, No.2, pp.249-270. DOI: doi.org/10.4040/jnas.1990.20.2.249

[16] S. J. Kwon, A Study on Consciousness of Bioethics of the Nursing Students and Medical Students, Master's Thesis, Keimyung Universuty, (2003)

[17] H. S. Jeong, Y. S. Park, G. R. Jeon, H. C. Park, J. S. Lee, A study on improving classroom classes to improve media literacy, Korea Sejong: Ministry of Education, (2015)

[18] H. J. Kim, H. Y. Kim, E. Y. Kim, M. A. Choi, A Study on Media Literacy Education Plan for Fostering Democratic Citizens, Research Report KR 2019-4, Korea: Korea Education and Research Information Service, (2019)

[19] S. Park, Dimensions of Digital Media Literacy and the Relationship with Social Exclusion, Media International Australia, (2012), DOI: https://doi.org/10.1177/1329878X1214200111 